\title{
Subtle changes in solar radiation under a green-to-red conversion film affect the photosynthetic performance and chlorophyll fluorescence of sweet pepper
}

\author{
H.I. YOON, J.H. KANG, W.H. KANG, and J.E. SON ${ }^{+}$ \\ Department of Agriculture, Forest and Bioresources (Horticultural Science and Biotechnology) and Research \\ Institute of Agriculture and Life Sciences, Seoul National University, 08826 Seoul, Korea
}

\begin{abstract}
Although spectrum conversion films are used to improve the photosynthetic efficiency and, ultimately, crop growth, the effects of the modified spectrum on photosynthetic traits in plants have not yet been sufficiently reported. The objective of this study was to investigate the changes in photosynthetic performance and chlorophyll fluorescence of sweet pepper (Capsicum annuиm L.) under a green-to-red conversion (GtR) film. The GtR-modified spectrum increased the dry mass and decreased the petiole length. The photosynthetic light-response curves were significantly improved, and the gap of the maximum photosynthetic rates increased over time after covering. The GtR-modified spectrum significantly increased chlorophyll fluorescence parameters in the JIP-test, such as parameters related to the reduction of end electron acceptors on the PSI acceptor side, the efficiency for electron transport in PSII, and the performance indexes. Our data indicated that the GtR-modified spectrum promotes electron transfer around PSI, improving photosynthetic performance and growth.
\end{abstract}

Additional key words: bell pepper; chlorophyll fluorescence transient; gas exchange; light adaptation; light quality.

\section{Introduction}

The research on the effects of light quality on plants has mostly focused on growth and morphology (Smith 1982, Patil et al. 2001, Li et al. 2003, Niinemets 2010, Stanton et al. 2010, Dieleman et al. 2019). Recently, research focusing on photosynthetic capacity according to light quality using artificial irradiance has been reported in detail. Different monochromatic lights, such as blue and red, affected not only growth and morphology but also chlorophyll (Chl) contents, stomatal conductance, and net photosynthetic rate (Lee et al. 2007). The different light qualities may alter the activity of the photosynthetic apparatus in leaves and the expression of the Calvin cycle enzymes, inducing changes in photosynthetic capacity (Wang et al. 2009). In addition, the effect of light quality on photosynthetic response could be interpreted by photosynthetic electron transport of PSII and PSI, cyclic electron flow (CEF), and other Chl fluorescence parameters (Yang et al. 2018). Plants perform different photosynthetic acclimation reactions depending on shortor long-term changes in light quality (Dietzel et al. 2008).

Greenhouse coverings, such as films, modify solar radiation coming into the greenhouse to create a light environment for plants. Spectrum conversion film (SCF) is a functional covering film that is used to improve the light spectrum for plant growth and photosynthesis (Lamnatou and Chemisana 2013). SCF converts lowefficiency wavelengths into high-efficiency wavelengths, such as ultraviolet to blue and green to red, based on spectral quantum yield for carbon fixation (McCree 1971, Paradiso et al. 2011). The film was called a green-to-red 'conversion' film, but to be precise, it absorbs green lights and emits red lights. Many research studies have shown the remarkable effects of SCF on yields in various crops, such as tomato, strawberry, radish, cucumber, and lettuce (Novoplansky et al. 1990, Hemming et al. 2006, Hidaka et al. 2008, Nishimura et al. 2012, Kwon et al. 2013, Park et al. 2016). Although SCFs have been developed to improve photosynthetic efficiency, the effects of the

Received 23 April 2020, accepted 9 August 2020, published online 24 September 2020.

${ }^{+}$Corresponding author; phone: +82 2 880-4564, fax: +82 2873 2056, e-mail: sjeenv@snu.ac.kr

Abbreviations: ABS/CS - absorption flux (exciting PSII antenna pigments) per exited cross-section; Area - complementary area above the fluorescence curve; $\mathrm{CEF}$ - cyclic electron flow; Chl - chlorophyll; DAC - days after covering; $\mathrm{DI}_{0} / \mathrm{CS}$ - dissipated energy flux per exited cross-section; $\mathrm{ET}_{0} / \mathrm{CS}$ - electron transport flux per exited cross-section; $\mathrm{M}_{0}$ - the initial slope of the fluorescence transient normalized on the maximal variable fluorescence; $\mathrm{PI}_{\mathrm{ABS}}$ - performance index on absorption basis; $\mathrm{PI}_{\text {total }}$ - total performance index; $P_{\mathrm{N}}-$ net photosynthetic rate; $P_{\mathrm{Nmax}}-$ light-saturated net photosynthetic rate; $R_{\mathrm{D}}-$ respiration rate; $\mathrm{RE} / \mathrm{CS}-$ energy flux reducing end electron acceptors at the PSI acceptor side, per exited cross-section; TR/CS - trapped energy flux (leading to $\mathrm{Q}_{\mathrm{A}}$ reduction) per exited cross-section; $\delta_{\mathrm{Ro}}-$ probability with which an electron from the intersystem electron carriers is transferred to reduce end electron acceptors at the PSI acceptor side (RE); $\theta$ - photosynthetic quantum yield at zero irradiance; $\varphi_{\mathrm{Eo}}-$ quantum yield for electron transport $(\mathrm{ET}) ; \varphi_{\mathrm{P}_{\mathrm{o}}}-$ maximum quantum yield for primary photochemistry; $\varphi_{\mathrm{R}_{\mathrm{o}}}$ - quantum yield for reduction of end electron acceptors at the PSI acceptor side (RE); $\psi_{\mathrm{E} o}$-probability with which an electron moves further than $\mathrm{Q}_{\mathrm{A}}^{-}$.

Acknowledgements: This work was supported by the Ministry of Trade, Industry and Energy, Republic of Korea (10052798). 
modified spectrum on photosynthetic traits in plants have not been fully reported.

Natural light is not monochromatic light but a spectrum of many different wavelengths that simultaneously affect plants. Subtle spectral changes in incident solar radiation, i.e., SCF-transmitted spectra, could not be interpreted solely according to previous research using monochromatic lights. Li et al. (2017) suggested that increasing CEF around PSI in Arabidopsis is one of the mechanisms by which SCF promotes $\mathrm{CO}_{2}$ fixation. A few research studies related to photosynthetic response under altered natural light were conducted using colored shade nets (Oliveira et al. 2016, Tafoya et al. 2018). Modified natural light environments, such as with photoselective film and screenhouses, affected the growth and photosynthetic acclimation of sweet pepper (Capsicum annuum L.), but the effect under SCF has not been reported yet (Li et al. 2000, Kong et al. 2013, Kitta et al. 2014a,b).

We wondered if the increase in photosynthetic efficiency through the SCF would actually lead to an increase in growth and, if so, how and when photosynthetic traits would change. Thus, the objective of this study was to investigate the SCF-induced effects on the growth, morphology, and photosynthetic performance through $\mathrm{Chl}$ fluorescence transient and gas-exchange parameters in sweet peppers.

\section{Materials and methods}

Plant material and growth conditions: Sweet pepper seedlings (Capsicum annuum L. cv Kori) were grown in a commercial nursery for $45 \mathrm{~d}$ and then transferred to a Venlo-type glass greenhouse at the experimental farm of Seoul National University, located in Suwon, Korea $\left(37^{\circ} 16^{\prime} \mathrm{N}, 126^{\circ} 59^{\prime} \mathrm{E}\right)$. The air temperature was set at $25 / 15^{\circ} \mathrm{C}$ day/night with roof vents and hot-water pipe systems. On 30 August 2019, the seedlings were transplanted into pots filled with commercial soils for horticultural crops (Baroker, Seoul Bio Co., Ltd., Eumseong, Korea). After transplanting, PBG nutrient solution from the Netherlands was applied with an electrical conductivity of $0.6 \mathrm{dS} \mathrm{m}^{-1}$ (de Kreij et al. 1999). At $32 \mathrm{~d}$ after transplanting, the pots were transferred to a small-sized greenhouse [2.0 (length) $\times$ 3.0 (width) $\times 2.0 \mathrm{~m}$ (height)] covered with experimental films, in which the upper leaves of plants were exposed to irradiance at a maximum intensity of $500 \mathrm{~W} \mathrm{~m} \mathrm{~m}^{-2}$ [approximately 2,300 $\mu \mathrm{mol}$ (photon) $\mathrm{m}^{-2} \mathrm{~s}^{-1}$ ] on sunny days. Four plants per treatment were harvested at $44 \mathrm{~d}$ after covering (DAC).

Film treatment and spectral characteristics: Experimental films used to cover the greenhouse included a commercial polyethylene (C-PE) film (Tajopyo PE, Taekwangnewtec Co., Ltd., Seoul, Korea) as the control and a spectrum conversion film, which converts green lights to red lights (GtR film), for the treatment condition. Light spectra under the C-PE and GtR films were measured using a spectroradiometer (BLUE-Wave spectrometer, StellarNet, Inc., Tampa, FL, USA) at the experimental site at 13:00 h on 6 October 2019. The total transmittance (sum of specular and diffuse transmittances) of the films was measured at room temperature using the spectroradiometer connected to an integrating sphere (IC-2, StellarNet, Inc.) in the range of 300 to $900 \mathrm{~nm}$. A solar simulator (XIL-01B50KPV1, SERIC, Ltd., Tokyo, Japan) was used as the light source. The transmittance was measured before covering and after harvest.

Growth and morphological parameters: As an early growth indicator, plant height, stem diameter, and the numbers of nodes and leaves were measured with six replicates at 5, 13, and $19 \mathrm{DAC}$. Growth and morphological parameters, including leaf length and width, petiole length, internode length, the number of leaves and nodes, and the fresh mass of leaves, stems, and fruits were measured with three plants at harvest (44 DAC). The internode length was calculated by dividing the total length of internodes by the number of nodes. Additionally, the SPAD value was measured using a Chl meter (SPAD-502, Konica Minolta, Tokyo, Japan) five times per replicate. The dry mass of leaves, stems, and fruits was measured after drying in an even at $70^{\circ} \mathrm{C}$ for $72 \mathrm{~h}$. The leaf area per plant was calculated using ImageJ 1.49 image analysis software (National Institutes of Health, Bethesda, MD, USA).

Gas-exchange measurement: Photosynthetic rates were measured using a portable photosynthetic system ( $L I$ $6400 X T, L i$-cor, Lincoln, NE, USA) and an LED light source (6400-02B, Li-cor). The fourth leaf from the top of the plant was used to measure the photosynthetic light curve with four replicates at 5, 13, and 44 DAC. Before all measurements, the leaves were adapted under the light source (approximately $15 \mathrm{~min}$ ) at a PPFD of 1,000 $\mu \mathrm{mol}\left(\right.$ photon) $\mathrm{m}^{-2} \mathrm{~s}^{-1}$. The conditions in the leaf chamber were kept constant (leaf temperature was $26.1 \pm 0.62^{\circ} \mathrm{C}$, relative humidity was $58.6 \pm 1.3 \%$, and $\mathrm{CO}_{2}$ concentration was $400 \mathrm{ppm})$. The measurements were taken at irradiance levels of 2,$000 ; 1,500 ; 1,200 ; 900,600,400,200,100,50$, and $0 \mu \mathrm{mol}$ (photon) $\mathrm{m}^{-2} \mathrm{~s}^{-1}$ PPFD. Light-response curves for $\mathrm{CO}_{2}$ assimilation were fitted to a rectangular hyperbola Michaelis-Menten-based model according to previous studies (Thornley 1976, Givnish 1988, Lobo et al. 2013):

$$
P_{\mathrm{N}}=-R_{\mathrm{D}}+\frac{P_{\mathrm{Nmax}} \times I}{P_{\mathrm{N} \max } / \theta+I}
$$

where $P_{\mathrm{N}}$ is the net photosynthetic rate $\left[\mu \mathrm{mol} \mathrm{m} \mathrm{m}^{-2} \mathrm{~s}^{-1}\right.$, $R_{\mathrm{D}}$ is dark respiration rate $\left[\mu \mathrm{mol} \mathrm{m} \mathrm{m}^{-2} \mathrm{~s}^{-1}\right], P_{\mathrm{Nmax}}$ is the maximum net photosynthetic rate $\left[\mu \mathrm{mol} \mathrm{m} \mathrm{m}^{-2} \mathrm{~s}^{-1}\right], I$ is the photosynthetic photon flux density $\left[\mu \mathrm{mol}\right.$ (photon) $\mathrm{m}^{-2} \mathrm{~s}^{-1}$, and $\theta$ is the quantum yield at $I=0 \mu \mathrm{mol}$ (photon) $\mathrm{m}^{-2} \mathrm{~s}^{-1}$.

Chl fluorescence transient: The Chl fluorescence transient was measured on intact leaves using a Chl fluorescence meter (Handy PEA, Hansatech, King's Lynn, UK) at 49 DAC. The middle part of the first fully expanded leaf was dark-adapted for 20 min using a leaf clip (HPEA/LC, Hansatech), with 16 replicates per treatment. Fast fluorescence transients were taken using a saturating pulse of 
1,500 $\mu \mathrm{mol}$ (photon) $\mathrm{m}^{-2} \mathrm{~s}^{-1}$, a pulse duration of $1 \mathrm{~s}$, and a fixed gain of $1 \times$. The $\mathrm{Chl}$ fluorescence kinetic parameters were obtained based on the theory of energy flow in PSII and using the JIP-test according to previous studies (Strasser et al. 2000, Rapacz 2007, Kosmala et al. 2012, Gururani et al. 2015, Stirbet et al. 2018, Yoon et al. 2020), as described in Appendix.

Statistical analysis: For all measurements, the means of the C-PE and GtR films were compared via Student's $t$-test with each replicate $(P<0.1,0.05$, and 0.01$) . R$ software $(R$ 3.6.2, $R$ Foundation, Vienna, Austria) was used for the statistical analysis containing the regression analysis of the light-response curve for photosynthesis.

\section{Results}

Spectral characteristics: The spectral distributions of solar radiation in a greenhouse covered with the C-PE and GtR films are shown in Fig. 1. The photon flux transmitted through the GtR film increased by $7 \%$ at the red wavelengths of $600-700 \mathrm{~nm}$, increased by $5.2 \%$ at the far-red wavelengths of 700-800 $\mathrm{nm}$, and decreased by $1.9 \%$ at the blue-green wavelengths of $400-600 \mathrm{~nm}$ compared to the C-PE film. The red and far-red (R:FR) ratios under the C-PE and GtR films were 1.27 and 1.29, respectively (1.31 without cover). The total transmittance of the GtR film increased by $3.4 \%$ at the red wavelengths and decreased by $0.6-0.7 \%$ at the blue-green wavelengths compared to the C-PE film (Fig. 2C, Table 1). The transmittance higher than $100 \%$ at the red wavelength was caused by GtR film, which means that the transmitted light was greater than the incident light. The transmittance of the films measured $49 \mathrm{~d}$ after covering decreased in all wavelength ranges compared to the situation before covering. The transmittance differences in the C-PE film before and after covering were greater than those of the GtR film, especially in the range of 600-750 nm.

Plant growth and morphology: The initial growth and morphology, such as the plant height, the number of nodes and leaves, in the sweet peppers grown under the GtR film were significantly higher than those under the C-PE film (Fig. 2). The plants under the GtR film were significantly taller by $6.2-7.6 \%$ at 5-19 DAC than those under the C-PE film. The height at 44 DAC was similar in the C-PE and GtR film treatments (data not shown). The stem diameters of the plants under the C-PE and GtR films were not significantly different. The numbers of nodes in the plants under the GtR film significantly increased by 12.3 and $5.9 \%$ at 5 and 13 DAC, respectively, compared to those under the C-PE film, but were not significantly different at 19 and 44 DAC (Fig. 2C, Table 2). The number of leaves under the GtR film was significantly higher than that under the C-PE film by $7.2 \%$ at 13 DAC, but was not significantly different in other measurement periods. At $44 \mathrm{DAC}$, the total dry mass (sum of the leaves, stems, and fruits) of the plants grown under the GtR film significantly increased by $19.1 \%$ compared to that under the C-PE film (Table 2). The petiole length of the plants under the GtR film significantly

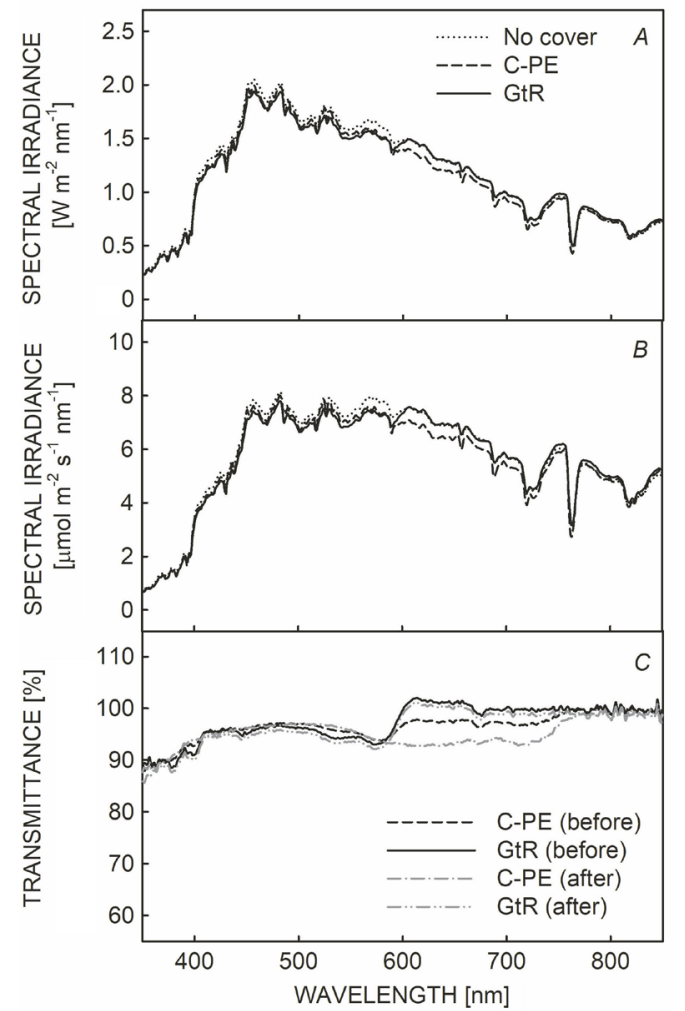

Fig. 1. Spectroscopic characteristics of the C-PE and GtR films. The spectral distributions of incident light under the films $(A, B)$ were measured in the experimental site at 13:00 h on 6 October 2019. The total transmittances $(C)$ were measured before and $49 \mathrm{~d}$ after covering using a spectroradiometer with an integrating sphere. The total transmittance (sum of specular and diffuse transmittances) was expressed as a percentage of incident light as $100 \%$.

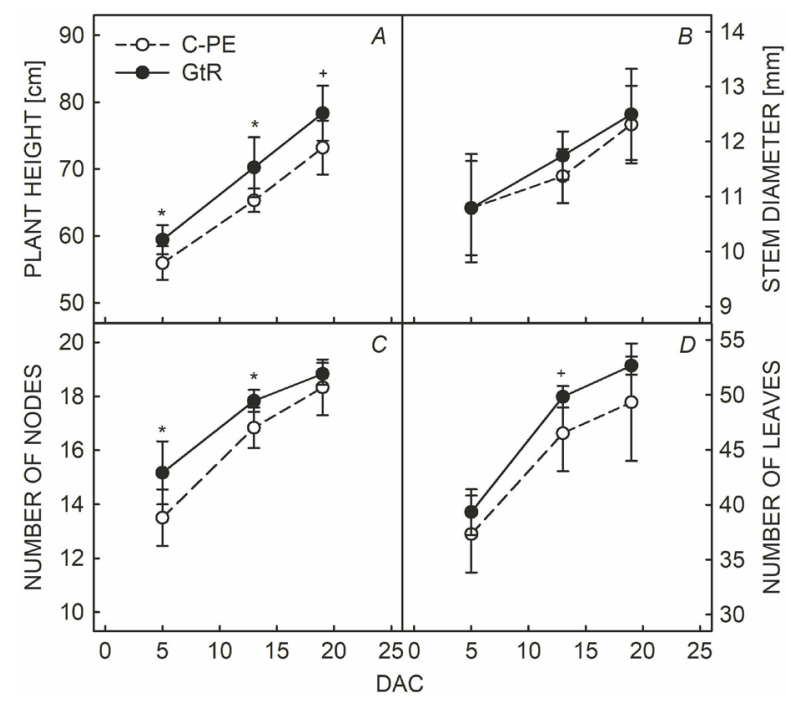

Fig. 2. Plant height $(A)$, stem diameter $(B)$, and the numbers of nodes $(C)$ and leaves $(D)$ of sweet pepper grown under the C-PE and GtR films at 5, 13, and $19 \mathrm{~d}$ after covering (DAC). The vertical bars indicate $\mathrm{SD}, n=6$. The symbols indicate significant differences (Student's $t$-test, ${ }^{+} P<0.1,{ }^{*} P<0.05$ ). 
Table 1. Spectral transmittance [\%] of the C-PE and GtR films before and $49 \mathrm{~d}$ after covering.

\begin{tabular}{lllrll}
\hline Spectrum & \multirow{2}{*}{ Range [nm] } & Before & & \multicolumn{2}{l}{ After (49 d) } \\
& & C-PE & GtR & C-PE & GtR \\
\hline Ultraviolet & $300-400$ & 89.4 & 90.0 & 88.0 & 89.1 \\
Blue & $400-500$ & 96.1 & 95.6 & 95.9 & 94.7 \\
Green & $500-600$ & 95.5 & 94.8 & 95.4 & 94.0 \\
Red & $600-700$ & 97.3 & 100.0 & 93.3 & 99.8 \\
PAR & $400-700$ & 96.3 & 97.0 & 94.9 & 96.2 \\
Far-red & $700-800$ & 98.4 & 99.8 & 96.2 & 98.9 \\
\hline
\end{tabular}

Table 2. Growth and morphology of the sweet peppers grown under the C-PE and GtR films at $44 \mathrm{~d}$ after covering. Data are presented as mean $\pm \mathrm{SD}(n=3)$. The plus $\left(^{+}\right)$indicates a significant difference at $P<0.1$ (Student's $t$-test). ns - not significant.

\begin{tabular}{lllll}
\hline Parameter & & C-PE & \multicolumn{1}{l}{ GtR } & \\
\hline Fresh mass [g] & Leaf & $234.7 \pm 1.2$ & $245.3 \pm 30.1$ & ns \\
& Stem & $137.3 \pm 3.1$ & $152.0 \pm 19.1$ & ns \\
& Fruit & $921.3 \pm 199.0$ & $1,157.3 \pm 74.5$ & ns \\
& Total & $1,293.3 \pm 198.0$ & $1,554.7 \pm 106.0$ & ns \\
Dry mass [g] & Leaf & $25.4 \pm 1.6$ & $28.1 \pm 3.5$ & ns \\
& Stem & $17.5 \pm 0.6$ & $19.1 \pm 2.3$ & ns \\
& Fruit & $47.2 \pm 10.1$ & $60.1 \pm 2.7$ & ns \\
& Total & $90.1 \pm 12.2$ & $107.3 \pm 6.2$ & + \\
Total number & Leaf & $52 \pm 5$ & $59 \pm 4$ & ns \\
& Fruit & $10 \pm 2$ & $11 \pm 1$ & ns \\
Internode length [nm] & $4.5 \pm 0.3$ & $4.6 \pm 0.4$ & ns \\
Leaf length [cm] & $21.2 \pm 0.5$ & $21.7 \pm 0.9$ & ns \\
Leaf width [cm] & $11.9 \pm 0.3$ & $12.3 \pm 1.2$ & ns \\
Petiole length [cm] & $11 \pm 0.4$ & $9.8 \pm 0.7$ & + \\
Leaf area [cm ${ }^{2}$ ] & $5,323.0 \pm 246.9$ & $5,661.1 \pm 698.1$ & ns \\
\hline
\end{tabular}

decreased by $10.2 \%$ compared to that under the C-PE film. The dry mass of fruits in the plants under the GtR film was $27.3 \%$ heavier than that under the C-PE film but not significantly different. The other parameters measured at harvest were not significantly different in the C-PE and GtR treatments. The SPAD values of leaves under the GtR film were $6.4 \%$ higher at $19 \mathrm{DAC}$ and $3.6 \%$ higher at 44 DAC than those under the C-PE film, but not significantly different (data not shown).

Photosynthetic light response: The difference in the net photosynthetic rate $\left(P_{\mathrm{N}}\right)$ for the sweet pepper leaves grown under the C-PE and GtR films was significantly and steadily greater over the days after covering (Fig. 3). At 5,13 , and $44 \mathrm{DAC}$, the parameters of the light-response curves are shown in Table 3 . The maximum photosynthetic rates $\left(P_{\mathrm{Nmax}}\right)$ under the GtR film increased by $2.0,29.1$, and $42.5 \%$ at 5,13 , and $44 \mathrm{DAC}$, respectively, compared to those under the C-PE film. The dark respiration $\left(R_{\mathrm{D}}\right)$ and quantum yield at zero irradiation $(\theta)$ under the GtR film increased at 5 DAC but decreased at 44 DAC

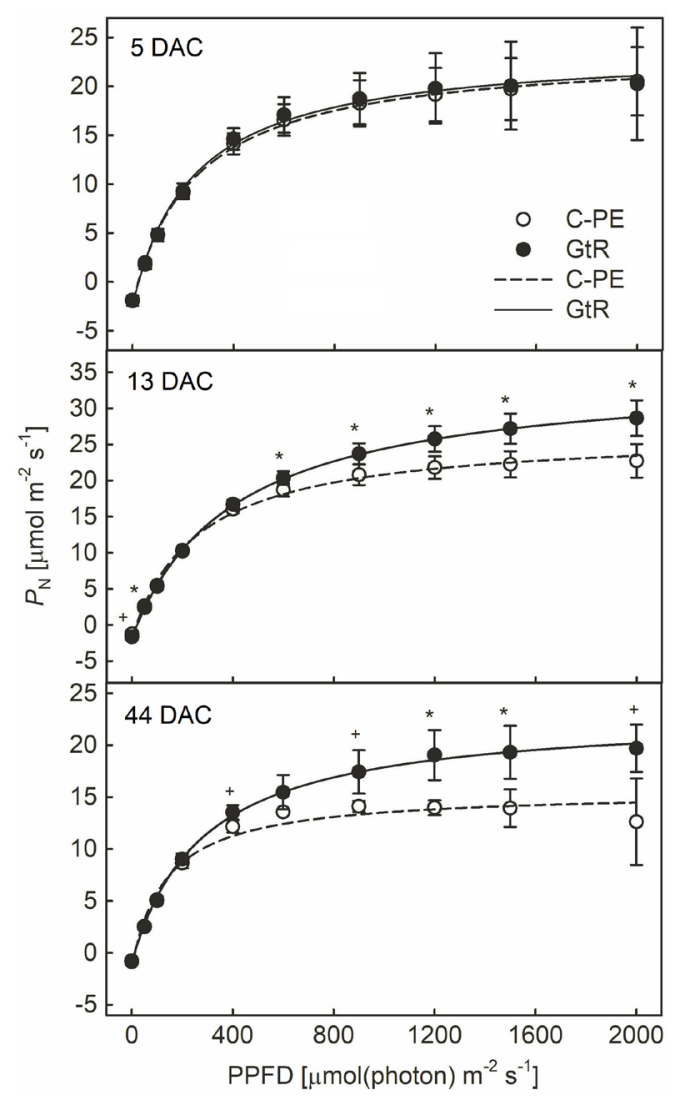

Fig. 3. Light-response curves of net photosynthesis $\left(P_{\mathrm{N}}\right)$ in the first fully expanded leaves of sweet pepper grown under the C-PE and GtR films at 5, 13, and $44 \mathrm{~d}$ after covering (DAC). The regression curves were obtained by Eq. 1, and the parameters refer to Table 3. The vertical bars indicate $\mathrm{SD}, n=3-4$. The symbols indicate significant differences (Student's $t$-test, $\left.{ }^{+} P<0.1,{ }^{*} P<0.05\right)$.

Table 3. The parameters $\left(R_{\mathrm{D}}, P_{\mathrm{Nmax}}\right.$, and $\left.\theta\right)$ and coefficient of determination $\left(R^{2}\right)$ for photosynthetic light-response curves of the sweet peppers grown under the C-PE and GtR films at 5, 13 , and $44 \mathrm{~d}$ after covering (DAC). $P_{\mathrm{Nmax}}-$ light-saturated net photosynthetic rate; $R_{\mathrm{D}}$ - respiration rate; $\theta$ - photosynthetic quantum yield at zero irradiance.

\begin{tabular}{|c|c|c|c|c|c|}
\hline DAC & Film & 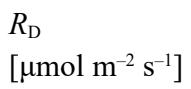 & $\begin{array}{l}P_{\mathrm{Nmax}} \\
{\left[\mu \mathrm{mol} \mathrm{m}{ }^{-2} \mathrm{~s}^{-1}\right]}\end{array}$ & $\theta$ & $R^{2}$ \\
\hline \multirow[t]{2}{*}{5} & C-PE & 2.159 & 25.804 & 0.104 & 0.956 \\
\hline & GtR & 2.425 & 26.315 & 0.111 & 0.919 \\
\hline \multirow[t]{2}{*}{13} & C-PE & 1.721 & 28.422 & 0.110 & 0.982 \\
\hline & GtR & 1.748 & 36.685 & 0.091 & 0.988 \\
\hline \multirow[t]{2}{*}{44} & C-PE & 1.360 & 16.910 & 0.124 & 0.922 \\
\hline & GtR & 0.995 & 24.101 & 0.087 & 0.967 \\
\hline
\end{tabular}

compared to those under the C-PE film. The coefficient of determination $\left(R^{2}\right)$ was very high and ranged from 0.919 to 0.988 , meaning that the rectangular hyperbola equation (Eq. 1) performed well to fit the light-response curves. 
Chl fluorescence transient: The Chl fluorescence transient parameters of the sweet pepper leaves grown under the C-PE and GtR films showed the spectrum-induced effects on PSII and PSI (Fig. 4). The parameters, such as the area between the fluorescence induction curve and the maximal fluorescence intensity (Area), the phenomenological energy flux reducing end electron acceptors at the PSI acceptor side per excited cross section $\left(\mathrm{RE}_{0} / \mathrm{CS}\right)$, the probability to move an electron further than $\mathrm{Q}_{\mathrm{A}}^{-}\left(\psi_{\mathrm{EO}}\right)$, the quantum yield for electron transport $\left(\varphi_{\mathrm{Eo}}\right)$, the probability that an electron is transported from reduced plastoquinone (PQ) to the electron acceptor side of PSI $\left(\delta_{\mathrm{Ro}}\right)$, the quantum yield for reduction of end electron acceptors at the PSI acceptor side $\left(\varphi_{\mathrm{Ro}}\right)$, and the performance indexes for energy conservation from exciton to the reduction of intersystem electron acceptors $\left(\mathrm{PI}_{\mathrm{ABS}}\right)$ and to the reduction of PSI end acceptors $\left(\mathrm{PI}_{\text {total }}\right)$, significantly increased under the GtR film compared to the C-PE film. The normalized initial slope (in $\mathrm{ms}^{-1}$ ) of the fluorescence transient $\left(\mathrm{M}_{0}\right)$ significantly decreased under GtR film compared to the C-PE film. The phenomenological energy fluxes absorbed by antenna pigments (ABS/CS), dissipated $\left(\mathrm{DI}_{0} / \mathrm{CS}\right)$, trapped in PSII reaction centers (TR/CS), and used for electron transport $\left(\mathrm{ET}_{0} / \mathrm{CS}\right)$ per excited cross-section, and the maximum quantum yield for primary photochemistry $\left(\varphi_{\mathrm{Po}}\right)$ under the C-PE and GtR films were quite similar. The specific energy fluxes (per $\mathrm{Q}_{\mathrm{A}}$-reducing PSII reaction center), i.e., $\mathrm{ABS} / \mathrm{RC}, \mathrm{DI}_{0} / \mathrm{RC}, \mathrm{TR} / \mathrm{RC}, \mathrm{ET}_{0} / \mathrm{RC}$, and $\mathrm{RE}_{0} / \mathrm{RC}$, of leaves grown under the C-PE and GtR films were consistent with the results of each phenomenological flux parameter (data not shown).

\section{Discussion}

We evaluated the cumulative effects of the modified solar spectrum on growth, morphology, the photosynthetic

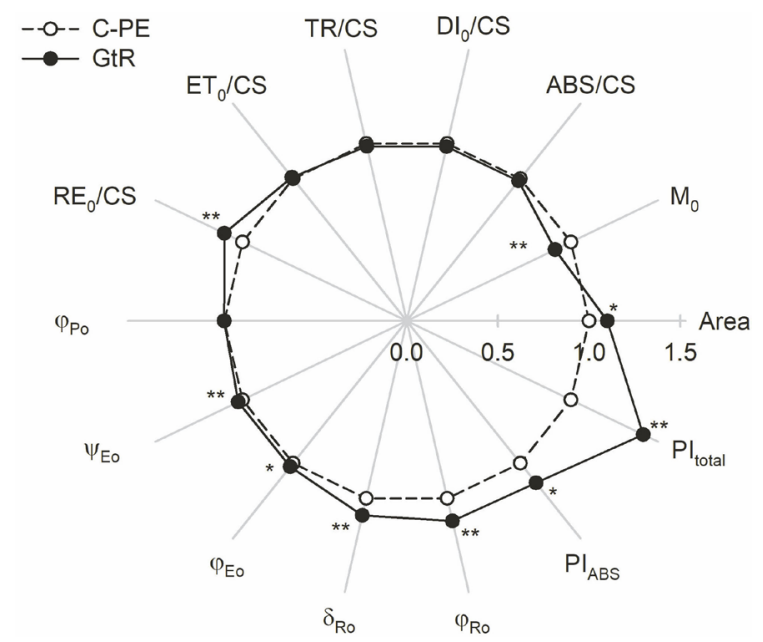

Fig. 4. Chlorophyll fluorescence parameters derived from JIPtest analyses in the first fully expanded leaves of sweet peppers grown under the C-PE and GtR films at $49 \mathrm{~d}$ after covering with 16 replicates. Each parameter was normalized on that of the C-PE in the plot and is described in the text. The asterisks indicate significant differences (Student's $t$-test, ${ }^{*} P<0.05,{ }^{* *} P<0.01$ ). light response, and $\mathrm{Chl}$ fluorescence transient in sweet peppers grown under a spectrum conversion film. This photoluminescence property is commonly measured using a spectrofluorometer (Pogreb et al. 2004, Wondraczek et al. 2013, El-Bashir et al. 2016, Qi et al. 2016). In this study, the spectral properties of the GtR film were evaluated at the experimental site and according to the total transmittance (Fig. 1). The transmitted spectra showed the modified spectrum actually reaching the crops, which is a general method for evaluating the properties of greenhouse covering materials (De Salvador et al. 2008, Kwon et al. 2017). Due to the luminescent properties of GtR film emitting red light in all directions, the total transmittance was measured using an integrating sphere (Schettini and Vox 2010). The photoluminescent effect of GtR film in the spectrum under solar radiation was less visible than that in the transmittance under the artificial lighting, which was consistent with other photoluminescent films (Schettini et al. 2011). The indoor measurements of total transmittance showed that the properties of the GtR film had changed less than $2 \%$ on day 44 after covering (Table 1 , Fig. 1C). The decreases in transmittance of red wavelengths indicate decreases in red emission, which are caused by photodegradation of the fluorescent dye molecules (El-Bashir et al. 2016). The long-term photostability of the film is an important obstacle for its use as a greenhouse cover but it did not have a large effect during the experiment described in this study.

The subtle changes in the solar spectrum could affect the growth and morphology of the sweet peppers grown under the GtR film. Although the initial effect of GtR on morphology was not maintained until harvest, the total dry mass significantly increased under the GtR film (Fig. 2, Table 2). Similarly, green-to-red SCFs improved the mass and yield in various crops, such as tomato, cucumber, and lettuce (Novoplansky et al. 1990, Nishimura et al. 2012, Park et al. 2016). In this study, the petiole length decreased under the GtR film, with a higher R:FR ratio than that of the C-PE film (Table 2). The extension of petiole growth is a phytochrome-regulated response, allowing the leaves to be placed in a light environment against the shade environment where R:FR ratio is low (Lötscher and Nösberger 1997, Ranwala et al. 2002). Since plants can increase the petiole length to improve light interception (Takenaka 1994, Duursma et al. 2012), it is possible that the diffuse light increased by the red light emission of the GtR film suppressed this elongation.

The cumulative effects of a modified spectrum on photosynthetic capacity could be evaluated as photosynthetic light response using the same LED light source. In this study, the difference in the light-response curves under the GtR and C-PE films did not appear on 5 DAC, occurred on 13 DAC, and remained until 44 DAC (at harvest), meaning that the cumulative effects improved the photosynthetic capacity in 1-2 weeks (Fig. 3). Similarly, Li et al. (2017) showed that the net photosynthetic rate in Arabidopsis grown under SCF significantly increased at PPFD of $1,200 \mu \mathrm{mol}\left(\right.$ photon) $\mathrm{m}^{-2} \mathrm{~s}^{-1}$ compared to the control. McCree (1971) reported that the spectral quantum yields for $\mathrm{CO}_{2}$ uptake were higher and had two maxima 
in the red and blue wavelengths, which is consistent with other research (Inada 1976, Paradiso et al. 2011). The increases in photosynthesis under the GtR film may be driven by the higher quantum yield of red light. However, this interpretation could not explain the results of measurements using the same LED light source, and it did not include the effects of photosynthetic acclimation. The long-term adaptation of plants to a specific environment over several days results from protein and pigment synthesis (Dau 1994). The plants subjected to a stable light quality gradient perceive the imbalanced photosystem excitation and respond by state transitions as a short-term response or readjustment of photosystem stoichiometry as a long-term response (Dietzel et al. 2008). Unfortunately, our findings were not sufficient to interpret these observations in detail, and further research is needed. The photosynthesis results were numerically compared with the parameters $\left(R_{\mathrm{D}}, P_{\mathrm{N} \max }\right.$, and $\left.\theta\right)$ of the photosynthetic model in Eq. 1 (Table 3). The rectangular hyperbola model is a simple model that describes the photosynthetic light-response curve (Chen et al. 2011, Lobo et al. 2013).

Furthermore, the modified spectrum affects the Chl fluorescence transient in sweet peppers grown under the GtR film, and its effects are only shown in particular parameters of the JIP-test (Fig. 4). The JIP-test, used to interpret the fluorescence signals into the phenomenology and biophysics of the photosynthetic apparatus, allows quantification of the functional photosynthetic properties and a detailed evaluation of the impact of the physiological state changes caused by separate treatments (Strasser et al. 2000, 2004; Tsimilli-Michael and Strasser 2008). The performance index, $\mathrm{PI}_{\mathrm{ABS}}$, is a multiparametric expression of three functional steps, i.e., light energy absorption (ABS), excitation energy trapping (TR), and conversion of excitation energy to electron transport (ET), which contribute to overall photosynthesis. The $\mathrm{PI}_{\mathrm{ABS}}$ is known as a sensitive parameter regardless of the type of plant and abiotic stress (Strauss et al. 2006, Živčák et al. 2008, Bussotti et al. 2010, Kalaji et al. 2012, Ceusters et al. 2019). Although the energy fluxes for $\mathrm{PI}_{\mathrm{ABS}}$-related parameters, i.e., $\mathrm{ABS} / \mathrm{CS}, \mathrm{TR} / \mathrm{CS}, \mathrm{ET} / \mathrm{CS}$, and $\varphi_{\mathrm{Po}}\left(=\mathrm{TR}_{0} / \mathrm{ABS}\right)$, were unchanged, the $\mathrm{PI}_{\mathrm{ABS}}$ significantly increased under the GtR film due to increases in $\psi_{\text {Eo }}$ and $\varphi_{\text {Eo }}$ (Fig. 4). The term Eo is related to electron transport from $\mathrm{Q}_{\mathrm{A}}^{-}$to the intersystem electron acceptors, i.e., Q $\mathrm{B}$, PQ pool, cytochrome $b_{6} f$, and plastocyanin. That is, the GtR-promoted photosynthetic efficiency in PSII was influenced by the electron transfer efficiency rather than the quantum yield of primary photochemistry $\left(\varphi_{P o}\right.$, called as $\left.F_{v} / F_{m}\right)$. Similarly, the commonly used $\varphi_{\mathrm{Po}}$ in various abiotic stresses is highly insensitive, while the $\mathrm{PI}_{\mathrm{ABS}}$ is more sensitive (TsimilliMichael and Strasser 2008, Živčák et al. 2008, Yoon et al. 2020). The normalized initial slope, $M_{0}$, expresses the net rate of electron trapping, increasing the number of closed reaction centers, and can be decreased by electron transport from $\mathrm{Q}_{\mathrm{A}}$ to $\mathrm{Q}_{\mathrm{B}}$ (Strasser et al. 2004, Stirbet and Govindjee 2011).

The terms RE and Ro represent the reduction of end acceptors at the PSI electron acceptor side, such as NADP and ferredoxin (Fd), and have been discussed recently (Tsimilli-Michael and Strasser 2008, Stirbet and Govindjee 2011, Stirbet et al. 2018). The total performance index, $\mathrm{PI}_{\text {total }}$, is an extended parameter of $\mathrm{PI}_{\mathrm{ABS}}$ and incorporates the performance up to the PSI end electron acceptors (RE); thus, it is the most sensitive parameter and expresses the overall potential for energy conservation (Yusuf et al. 2010, Gururani et al. 2015). In this study, the modified spectrum under the GtR film induced significant increases in all RE-related parameters, such as $\mathrm{RE}_{0} / \mathrm{CS}$, $\delta_{\text {Ro }}, \varphi_{\text {Ro }}$, and $\mathrm{PI}_{\text {total }}$ (Fig. 4). We can therefore deduce that the photosynthetic performance around the PSI electron acceptor side was enhanced and resulted from the increased energy flux, efficiency, and quantum yield for the reduction of end acceptors at the PSI side, such as NADP and Fd. Light quality could dynamically affect the CEF around PSI by state transition and photosystem stoichiometry readjustments, including the thylakoid membrane system (Wollman 2001, Allen 2003, Dietzel et al. 2008). Li et al. (2017) proposed that alteration to the spectrum by SCF could lead to variations in electron flow and increased CEF around PSI. The authors showed that the Fd-dependent PQ reduction level increased in WT Arabidopsis grown under SCF, whereas the increases did not appear in mutant pgr5, which lacks functions of the PROTON GRADIENT REGULATION 5 protein and is defective in Fd-dependent CEF, regardless of the film used. In addition, their results are in line with ours, which indicate the increased efficiency for electron transfer ( $\psi_{\mathrm{Eo}}$ and $\left.\varphi_{\mathrm{Eo}}\right)$ and the increased PQ pool reduction (Area) here (Fig. 4). If so, the increased CEF by the SCF-modified spectrum could improve the electron transport capacity and $\mathrm{RE}$ capacity, accelerating $\mathrm{CO}_{2}$ fixation.

This study compared the growth, morphology, and photosynthesis of sweet peppers over time after covering with a green-to-red conversion film and investigated the photosynthetic responses through $\mathrm{Chl}$ fluorescence transient and gas-exchange parameters in detail. The solar radiation with red light emission by the GtR film induced photosynthetic acclimation, affecting the growth and morphology of the plants. The photosynthetic light-response curves and $P_{\mathrm{Nmax}}$ showed that the cumulative effects of the GtR-modified spectrum improved the photosynthetic capacity after only two weeks. In the Chl fluorescence transient, the spectrum increased the efficiency of electron transfer up to intersystem electron acceptors $\left(\psi_{\mathrm{Eo}}, \varphi_{\mathrm{EO}}\right)$. The parameters related to the reduction of end acceptors at the PSI electron acceptor side $\left(\mathrm{RE}_{0} / \mathrm{CS}, \delta_{\mathrm{Ro}}, \varphi_{\mathrm{Ro}}\right.$, and $\left.\mathrm{PI}_{\text {total }}\right)$ were mostly changed, and the photosynthetic capacities were promoted under the GtR film. We concluded that the subtle changes in solar radiation modified by the GtR film could promote the electron transfer around PSI, improving the photosynthetic capacity and plant growth.

\section{References}

Allen J.F.: State transitions - A question of balance. - Science 299: 1530-1532, 2003.

Bussotti F., Desotgiu R., Pollastrini M., Cascio C.: The JIP test: A tool to screen the capacity of plant adaptation to climate change. - Scand. J. Forest Res. 25: 43-50, 2010.

Ceusters N., Valcke R., Frans M. et al.: Performance index and 
PSII connectivity under drought and contrasting light regimes in the CAM orchid Phalaenopsis. - Front. Plant Sci. 10: 1012, 2019.

Chen Z.Y., Peng Z.S., Yang J. et al.: A mathematical model for describing light-response curves in Nicotiana tabacum L. Photosynthetica 49: 467-471, 2011.

Dau H.: New trends in photobiology: Short-term adaptation of plants to changing light intensities and its relation to Photosystem II photochemistry and fluorescence emission. J. Photoch. Photobio. B 26: 3-27, 1994.

de Kreij C., Voogt W., Baas R.: Nutrient Solutions and Water Quality for Soilless Cultures. Pp. 32. Research Station for Floriculture and Glasshouse Vegetables, Naaldwijk 1999.

De Salvador F.R., Scarascia Mugnozza G., Vox G. et al.: Innovative photoselective and photoluminescent plastic films for protected cultivation. - Acta Hortic. 801: 115-122, 2008.

Dieleman J.A., De Visser P.H.B., Meinen E. et al.: Integrating morphological and physiological responses of tomato plants to light quality to the crop level by 3D modeling. - Front. Plant Sci. 10: 839, 2019.

Dietzel L., Bräutigam K., Pfannschmidt T.: Photosynthetic acclimation: State transitions and adjustment of photosystem stoichiometry - functional relationships between short-term and long-term light quality acclimation in plants. - FEBS J. 275: 1080-1088, 2008.

Duursma R.A., Falster D.S., Valladares F. et al.: Light interception efficiency explained by two simple variables: a test using a diversity of small- to medium-sized woody plants. - New Phytol. 193: 397-408, 2012.

El-Bashir S.M., Al-Harbi F.F., Elburaih H. et al.: Red photoluminescent PMMA nanohybrid films for modifying the spectral distribution of solar radiation inside greenhouses. Renew. Energ. 85: 928-938, 2016.

Givnish T.: Adaptation to sun and shade: A whole-plant perspective. - Funct. Plant Biol. 15: 63-92, 1988.

Gururani M.A., Venkatesh J., Ganesan M. et al.: In vivo assessment of cold tolerance through chlorophyll- $a$ fluorescence in transgenic zoysiagrass expressing mutant phytochrome A. PLoS ONE 10: e0127200, 2015.

Hemming S., van Os E.A., Hemming J., Dieleman J.A.: The effect of new developed fluorescent greenhouse films on the growth of Fragaria $\times$ ananassa "Elsanta". - Eur. J. Hortic. Sci. 71: 145-154, 2006.

Hidaka K., Yoshida K., Shimasaki K.: Spectrum conversion film for regulation of plant growth. - J. Fac. Agric. Kyushu Univ. 53: 549-552, 2008.

Inada K.: Action spectra for photosynthesis in higher plants. Plant Cell Physiol. 17: 355-365, 1976.

Kalaji H.M., Carpentier R., Allakhverdiev S.I., Bosa K.: Fluorescence parameters as early indicators of light stress in barley. - J. Photoch. Photobio. B 112: 1-6, 2012.

Kitta E., Baille A.D., Katsoulas N. et al.: Effects of cover optical properties on screenhouse radiative environment and sweet pepper productivity. - Biosyst. Eng. 122: 115-126, 2014a.

Kitta E., Katsoulas N., Kandila A. et al.: Photosynthetic acclimation of sweet pepper plants to screenhouse conditions. HortScience 49: 166-172, 2014b.

Kong Y., Avraham L., Perzelan Y. et al.: Pearl netting affects postharvest fruit quality in 'Vergasa' sweet pepper via light environment manipulation. - Sci. Hortic.-Amsterdam 150: 290-298, 2013.

Kosmala A., Perlikowski D., Pawłowicz I., Rapacz M.: Changes in the chloroplast proteome following water deficit and subsequent watering in a high- and a low-drought-tolerant genotype of Festuca arundinacea. - J. Exp. Bot. 63: 61616172, 2012.
Kwon J.-K., Park K.-S., Choi H.-G. et al:: Growth and developmental characteristics of lettuce, tomato and melon grown under spectrum conversion greenhouse films. J. Agric. Life Sci. 47: 57-63, 2013.

Kwon J.K., Khoshimkhujaev B., Lee J.H. et al.: Growth and yield of tomato and cucumber plants in polycarbonate or glass greenhouses. - Korean J. Hortic. Sci. 35: 79-87, 2017.

Lamnatou C., Chemisana D.: Solar radiation manipulations and their role in greenhouse claddings: Fluorescent solar concentrators, photoselective and other materials. - Renew. Sust. Energ. Rev. 27: 175-190, 2013.

Lee S.-H., Tewari R.K., Hahn E.-J., Paek K.Y.: Photon flux density and light quality induce changes in growth, stomatal development, photosynthesis and transpiration of Withania somnifera (L.) Dunal. plantlets. - Plant Cell. Tiss. Org. 90: 141-151, 2007.

Li S., Rajapakse N.C., Young R.E.: Far-red light absorbing photoselective plastic films affect growth and flowering of chrysanthemum cultivars. - HortScience 38: 284-287, 2003.

Li S., Rajapakse N.C., Young, R.E., Oi R.: Growth responses of chrysanthemum and bell pepper transplants to photoselective plastic films. - Sci. Hortic.-Amsterdam 84: 215-225, 2000.

Li Y., Tu W., Liu C. et al.: Light conversion film promotes $\mathrm{CO}_{2}$ assimilation by increasing cyclic electron flow around Photosystem I in Arabidopsis thaliana. - Int. J. Hydrogen Energ. 42: 8545-8553, 2017.

Lobo F. de A., de Barros M.P., Dalmagro H.J. et al.: Fitting net photosynthetic light-response curves with Microsoft Excel a critical look at the models. - Photosynthetica 51: 445-456, 2013.

Lötscher M., Nösberger J.: Branch and root formation in Trifolium repens is influenced by the light environment of unfolded leaves. - Oecologia 111: 499-504, 1997.

McCree K.J.: The action spectrum, absorptance and quantum yield of photosynthesis in crop plants. - Agric. Meteorol. 9: 191-216, 1971.

Niinemets Ü.: A review of light interception in plant stands from leaf to canopy in different plant functional types and in species with varying shade tolerance. - Ecol. Res. 25: 693-714, 2010.

Nishimura Y., Wada E., Fukumoto Y. et al.: The effect of spectrum conversion covering film on cucumber in soilless culture. Acta Hortic. 956: 481-487, 2012.

Novoplansky A., Sachs T., Cohen D. et al.: Increasing plant productivity by changing the solar spectrum. - Sol. Energ. Mat. 21: 17-23, 1990.

Oliveira G.C., Vieira W.L., Bertolli S.C., Pacheco A.C.: Photosynthetic behavior, growth and essential oil production of Melissa officinalis L. cultivated under colored shade nets. - Chil. J. Agr. Res. 76: 123-128, 2016.

Paradiso R., Meinen E., Snel J.F.H. et al:: Spectral dependence of photosynthesis and light absorptance in single leaves and canopy in rose. - Sci. Hortic.-Amsterdam 127: 548-554, 2011.

Park K.S., Kwon J.K., Lee D.K., Son J.E.: Microclimate and crop growth in the greenhouses covered with spectrum conversion films using different phosphor particle sizes. Protect. Hortic. Plant Fact. 25: 111-117, 2016. doi: 10.12791/ KSBEC.2016.25.2.111 [In Korean]

Patil G.G., Oi R., Gissinger A., Moe R.: Plant morphology is affected by light quality selective plastic films and alternating day and night temperature. - Gartenbauwissenschaft 66: 53-60, 2001.

Pogreb R., Finkelshtein B., Shmukler Y. et al.: Low-density polyethylene films doped with europium(III) complex: Their properties and applications. - Polym. Adv. Technol. 15: 414-418, 2004.

Qi Y., Wang Y., Yu Y. et al.: Exploring highly efficient light 
conversion agents for agricultural film based on aggregation induced emission effects. - J. Mater. Chem. C 4: 1129111297, 2016.

Ranwala N.K.D., Decoteau D.R., Ranwala A.P. et al.: Changes in soluble carbohydrates during phytochrome-regulated petiole elongation in watermelon seedlings. - Plant Growth Regul. 38: 157-163, 2002.

Rapacz M.: Chlorophyll $a$ fluorescence transient during freezing and recovery in winter wheat. - Photosynthetica 45: 409-418, 2007.

Schettini E., De Salvador F.R., Scarascia-Mugnozza G., Vox G.: Radiometric properties of photoselective and photoluminescent greenhouse plastic films and their effects on peach and cherry tree growth. - J. Hortic. Sci. Biotech. 86: 79-83, 2011.

Schettini E., Vox G.: Greenhouse plastic films capable of modifying the spectral distribution of solar radiation. J. Agric. Eng. 41: 19, 2010.

Smith H.: Light quality, photoperception, and plant strategy. Ann. Rev. Plant Physio. 33: 481-518, 1982.

Stanton K.M., Weeks S.S., Dana M.N., Mickelbart M.V.: Light exposure and shade effects on growth, flowering, and leaf morphology of Spiraea alba Du Roi and Spiraea tomentosa L. - HortScience 45: 1912-1916, 2010.

Stirbet A., Govindjee: On the relation between the Kautsky effect (chlorophyll $a$ fluorescence induction) and Photosystem II: Basics and applications of the OJIP fluorescence transient. J. Photoch. Photobio. B Biol. 104: 236-257, 2011.

Stirbet A., Lazár D., Kromdijk J., Govindjee: Chlorophyll $a$ fluorescence induction: Can just a one-second measurement be used to quantify abiotic stress responses? - Photosynthetica 56: 86-104, 2018.

Strasser R.J., Srivastava A., Tsimilli-Michael M.: The fluorescence transient as a tool to characterize and screen photosynthetic samples. - In: Yunus M., Pathre U., Mohanty P. (ed.): Probing Photosynthesis: Mechanisms, Regulation and Adaptation. Pp. 445-483. Taylor \& Francis, London 2000.

Strasser R.J., Tsimilli-Michael M., Srivastava A.: Analysis of the chlorophyll $a$ fluorescence transient. - In: Papageorgiou G.C., Govindjee (ed.): Chlorophyll $a$ Fluorescence: A Signature of Photosynthesis. Advances in Photosynthesis and Respiration. Pp. 321-362. Springer, Dordrecht 2004.

Strauss A.J., Krüger G.H.J., Strasser R.J., Van Heerden P.D.R.: Ranking of dark chilling tolerance in soybean genotypes probed by the chlorophyll $a$ fluorescence transient O-J-I-P. Environ. Exp. Bot. 56: 147-157, 2006.

Tafoya F.A., Juárez M.G.Y., Orona C.A.L. et al.: Sunlight transmitted by colored shade nets on photosynthesis and yield of cucumber. - Ciênc. Rural 48: 09, 2018.

Takenaka A.: Effects of leaf blade narrowness and petiole length on the light capture efficiency of a shoot. - Ecol. Res. 9: 109-114, 1994.

Thornley J.H.M.: Mathematical Models in Plant Physiology. Pp. 318. Academic Press, London 1976.

Tsimilli-Michael M., Strasser R.J.: In vivo assessment of stress impact on plants' vitality: applications in detecting and evaluating the beneficial role of mycorrhization on host plants. In: Varma A. (ed.): Mycorrhiza. State of the Art, Genetics and Molecular Biology, Eco-Function, Biotechnology, EcoPhysiology, Structure and Systematics. $3^{\text {rd }}$ edition. Pp. 679703. Springer, Berlin-Heidelberg 2008.

Wang H., Gu M., Cui J. et al.: Effects of light quality on $\mathrm{CO}_{2}$ assimilation, chlorophyll-fluorescence quenching, expression of Calvin cycle genes and carbohydrate accumulation in Cucumis sativus. - J. Photoch. Photobio. B 96: 30-37, 2009.

Wollman F.-A.: State transitions reveal the dynamics and flexibility of the photosynthetic apparatus. - EMBO J. 20: 3623-3630, 2001.

Wondraczek L., Batentschuk M., Schmidt M.A. et al.: Solar spectral conversion for improving the photosynthetic activity in algae reactors. - Nat. Commun. 4: 2047, 2013.

Yang X., Xu H., Shao L. et al.: Response of photosynthetic capacity of tomato leaves to different LED light wavelength. Environ. Exp. Bot. 150: 161-171, 2018.

Yoon H.I., Kim D., Son J.E.: Spatial and temporal bioactive compound contents and chlorophyll fluorescence of kale (Brassica oleracea L.) under UV-B exposure near harvest time in controlled environments. - Photochem. Photobiol. 96: 845-852, 2020.

Yusuf M.A., Kumar D., Rajwanshi R. et al.: Overexpression of $\gamma$-tocopherol methyl transferase gene in transgenic Brassica juncea plants alleviates abiotic stress: Physiological and chlorophyll $a$ fluorescence measurements. - BBABioenergetics 1797: 1428-1438, 2010.

Živčák M., Brestič M., Olšovská K., Slamka P.: Performance index as a sensitive indicator of water stress in Triticum aestivum L. - Plant Soil Environ. 54: 133-139, 2008.

Appendix. Formulae and glossary of terms used by the JIP-test in the study (modified after Strasser et al. 2004).

Data extracted from the recorded fluorescence transient OJIP

$\begin{array}{ll}\mathrm{F}_{\mathrm{t}} & \text { fluorescence at time } \mathrm{t} \text { after the onset of actinic illumination } \\ \mathrm{F}_{0}=\mathrm{F}_{50 \mu \mathrm{s}} & \text { minimal fluorescence intensity }(50 \mu \mathrm{s}) \\ \mathrm{F}_{300 \mu \mathrm{s}} & \text { fluorescence intensity at } 300 \mu \mathrm{s} \\ \mathrm{F}_{\mathrm{J}}=\mathrm{F}_{2 \mathrm{~ms}} & \text { fluorescence intensity at the J-step }(2 \mathrm{~ms}) \text { of OJIP } \\ \mathrm{F}_{\mathrm{I}}=\mathrm{F}_{30 \mathrm{~ms}} & \text { fluorescence intensity at the I-step }(30 \mathrm{~ms}) \text { of OJIP } \\ \mathrm{F}_{\mathrm{M}}=\mathrm{F}_{\mathrm{P}} & \text { maximal fluorescence intensity, at the peak P of OJIP } \\ \text { Area } & \text { total complementary area between the fluorescence induction curve and } \mathrm{F}_{\mathrm{M}}\end{array}$

Fluorescence parameters derived from the extracted data

$$
\begin{array}{rlrl}
\mathrm{F}_{\mathrm{V}} & =\mathrm{F}_{\mathrm{M}}-\mathrm{F}_{0} & & \text { maximal variable fluorescence } \\
\mathrm{V}_{\mathrm{t}} & =\left(\mathrm{F}_{\mathrm{t}}-\mathrm{F}_{0}\right) / \mathrm{F}_{\mathrm{V}} & & \text { relative variable fluorescence } \\
\mathrm{M}_{0} & =(\Delta \mathrm{V} / \Delta \mathrm{t})_{0} & & \text { initial slope }\left(\text { in } \mathrm{ms}^{-1}\right) \text { of the } \mathrm{O}-\mathrm{J} \text { fluorescence rise } \\
& \approx 4 \times\left[\left(\mathrm{F}_{300 \mu \mathrm{s}}-\mathrm{F}_{50 \mu \mathrm{s}}\right) /\left(\mathrm{F}_{\mathrm{M}}-\mathrm{F}_{50 \mu \mathrm{s}}\right)\right] &
\end{array}
$$


Specific energy fluxes (per $\mathrm{Q}_{\mathrm{A}}$-reducing PSII reaction center - RC)

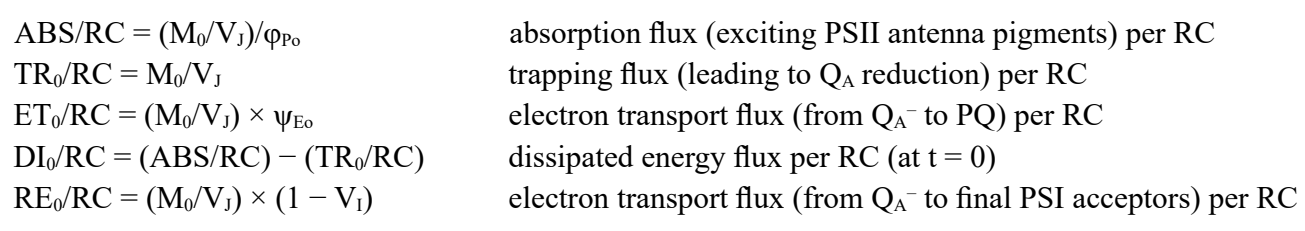

Quantum yields and efficiencies

$\psi_{\mathrm{Eo}}=\mathrm{ET}_{0} / \mathrm{TR}_{0}=1-\mathrm{V}_{\mathrm{J}}$

$\psi_{\mathrm{Ro}}=\mathrm{RE}_{0} / \mathrm{TR}_{0}=1-\mathrm{V}_{\mathrm{I}}$

$\delta_{\mathrm{Ro}}=\mathrm{RE}_{0} / \mathrm{ET}_{0}=\psi_{\mathrm{Ro}} / \psi_{\mathrm{Eo}}$

$\varphi_{\mathrm{Po}_{\mathrm{o}}}=\mathrm{TR}_{0} / \mathrm{ABS}=\mathrm{F}_{\mathrm{V}} / \mathrm{F}_{\mathrm{M}}$

$\varphi_{\mathrm{Ro}_{0}}=\mathrm{RE}_{0} / \mathrm{ABS}=\varphi_{\mathrm{Po}_{0}} /\left(1-\mathrm{V}_{\mathrm{I}}\right)$

$\varphi_{\mathrm{Eo}}=\mathrm{ET}_{0} / \mathrm{ABS}=\varphi_{\mathrm{Po}_{\mathrm{o}}} /\left(1-\mathrm{V}_{\mathrm{J}}\right)$

Phenomenological fluxes

$\mathrm{ABS} / \mathrm{CS}=\left(\mathrm{M}_{0} / \mathrm{V}_{\mathrm{J}}\right) / \varphi_{\mathrm{Po}_{\mathrm{o}}}$

$\mathrm{TR} / \mathrm{CS}=\left(\mathrm{TR}_{0} / \mathrm{ABS}\right) \times(\mathrm{ABS} / \mathrm{CS})$

$\mathrm{ET}_{0} / \mathrm{CS}=\left(\mathrm{ET}_{0} / \mathrm{ABS}\right) \times(\mathrm{ABS} / \mathrm{CS})$

$\mathrm{DI}_{0} / \mathrm{CS}=\left(\mathrm{DI}_{0} / \mathrm{ABS}\right) \times(\mathrm{ABS} / \mathrm{CS})$

probability that a trapped exciton moves an electron into the electron transport chain beyond $\mathrm{Q}_{\mathrm{A}}$

probability that a trapped exciton moves an electron into final PSI acceptors

efficiency with which an electron from the intersystem electron carriers moves to reduce final PSI acceptors

maximum quantum yield of primary PSII photochemistry

quantum yield for reduction of end electron acceptors at the PSI acceptor side

quantum yield of electron transport (at $\mathrm{t}=0$ )

$\mathrm{RE}_{0} / \mathrm{CS}=\left(\mathrm{RE}_{0} / \mathrm{ABS}\right) \times(\mathrm{ABS} / \mathrm{CS})$

absorption flux per excited cross section of PSII

trapping flux per excited cross section of PSII

electron transport flux per excited cross section of PSII

dissipated energy flux per excited cross section of PSII

electron flux reducing end electron acceptors at the PSI acceptor side per excited cross section of PSII

Performance indexes

$\mathrm{PI}_{\mathrm{ABS}}=(\mathrm{RC} / \mathrm{ABS}) \times\left[\varphi_{\mathrm{Po}_{\mathrm{o}}} /\left(1-\varphi_{\mathrm{P}_{\mathrm{O}}}\right)\right] \times$ performance index on absorption basis $\left[\psi_{\mathrm{Eo}} /\left(1-\psi_{\mathrm{Eo}}\right)\right]$

$\mathrm{PI}_{\text {total }}=\mathrm{PI}_{\mathrm{ABS}} \times\left[\delta_{\mathrm{Ro}} /\left(1-\delta_{\mathrm{Ro}}\right)\right] \quad$ total performance index on absorption basis

(C) The authors. This is an open access article distributed under the terms of the Creative Commons BY-NC-ND Licence. 